\title{
Research on the application of interactive evaluation on Moodle platform in Distance Education
}

\author{
Zhu Peiping \\ Department of physical science and technology, Kunming University, Kunming,China,650214 \\ 3267002772@qq.com
}

\section{Keywords: Moodle, Interactive evaluation, Distance Learning, Application Research}

Abstract: This paper discusses the problem of the evaluation in distance education. Base on the characteristics of distance education that teachers and students' space and time separation, and the course requirements. In this paper, the students in the learning process exists common problems — students' learning is difficult to evaluation. In this paper, combined with specific example, the author introduces the interactive evaluation in distance learning of Moodle platform, and in-depth analysis of the application of the method.

\section{Introduction}

With the rapid development of internet technology and the popularization of personal computers, the form of distance education has enormous changed. The learning style of students is constantly changing. Schools were form mailed teaching material to students to establish the specialized curriculum website to students. Teaching materials are also from the original text transmission to multimedia presentation. With the development of information technology and the improvement of teaching methods, although teaching materials and teaching methods are constantly updated, the interaction between teachers and students is still unsatisfactory. Teachers' evaluation of students is also just stay in the students' feedback of homework and papers. In some network courses, teachers are relatively strict in the daily management of students. To complete a course, students are required to participate in the corresponding learning activities and submit homework. All of those are evaluated by teachers. Such an evaluation is subjective, and the workload of teachers is also very large. If teachers use the interactive evaluation on the Moodle platform, it can make the students participate in the evaluation, which can make the evaluation more objective and fair, and also help to mobilize the learn enthusiasm of students.

\section{Literature review}

According to the author from the literature review, there are few literatures about the interactive evaluation on Moodle platform. Some articles just do a simple introduction from the functions application. They are not from the overall analysis of the interactive evaluation. In this paper, the specific application of the interactive evaluation to do a detailed introduction. This article makes a detailed explanation, which is helpful for the readers to understand and apply the interactive evaluation more comprehensively and profoundly.

\section{Moodle platform and evaluation function}

Moodle's full name is Object-Oriented Dynamic Learning Environment Modular. Moodle is a software package for making web courses or web sites1. Moodle also describes the process of a gradual process and a process that can lead the learner to gain insight and creativity. Because of this, the Moodle curriculum management system is not only applied to the development of Moodle, but also 
applied to the students and teachers' online course learning or teaching. Moodle can also help educators to establish effective online learning communities.

Moodle platform as a course management and learning management systems, not only has a series of functions, such as development resource,creation activities and perfect control, but also has advanced educational concept and easy to operate with modular design, open source and other characteristics, which is welcomed by teachers. Modular design and object-oriented development method separates data access and user interface, which has good flexibility and scalability1. Moodle also has a plurality of curricular activities modules. According to the needs of teaching, teachers can select the appropriate modules, create an interactive environment for teaching activities.

Interactive evaluation is a special activity module in Moodle. The interaction evaluation reflects the diversification of the evaluation body. It can be combined with student self-assessment, mutual evaluation of students and teacher evaluation, so as to improve the objectivity and accuracy of the evaluation results.

\section{Advantages of interactive evaluation based on Moodle platform}

\subsection{Diversification of evaluation strategies}

Moodle offers five different evaluation methods, namely grade evaluation, error range, standard, cumulative and gauge. The error range, standard, and gauge four scoring strategies are composed of a series of evaluation elements and evaluation criteria.Implementation of distance education teacher, according to the teaching content, the teacher selects the appropriate evaluation methods, gives students a proper and fair evaluation, so that the results of the evaluation to make students more convincing.

4.2 Interactive evaluation can make the evaluation more objective and comprehensive.

In the traditional distance education, the students have nothing to do after they finish their homework. After class, teacher has marked the students' homework.Students can not participate in the evaluation job. Using the interactive evaluation of moodle platform, teacher can design a lot of parameters before the evaluation, to enable students to participate in the process of correcting homework. Students can carry out self-evaluation, can evaluate other students' homework, the teacher can evaluate students for secondary evaluation. It can avoid the interference of human and emotion in the process of evaluation, thus ensuring the comprehensive, objective and fair of the evaluation.

4.3 Interactive evaluation can mobilize the enthusiasm of students to learn and participate in classroom teaching.

The traditional distance education mostly stays in the condition that the teacher speaks, the students listen.Students are rarely involved in the teaching process. Although interactive teaching can also be seen in the recent distance education, but it is only stay in the teaching process, the majority of students are very valued assignments and assessment score.Students have no right to intervene2. The interactive evaluation can make all the students participate in the evaluation and assessment of the work, so that students have the "right to speak", which greatly improves the learning initiative and enthusiasm of students. Students can play a good role in oversight and supervision between classmates.

4.4 The results of interactive evaluation are easy to obtain.

For a job, through the Moodle platform to carry out interactive evaluation. Teachers and students only need to give their ratings, a large number of statistical work is done by the Moodle. The final 
results will be automatically displayed to the teachers and students3. Teachers can view each student's grades and other students gave to his score. Students can view their results as well as other students gave their scores. Interactive evaluation results will be permanently retained on the Moodle platform, teachers and students can log on to the platform at any time.

\section{Teaching practice of interactive evaluation based on Moodle platform}

The author according to her teaching of "distance education" as an example, She were integrated the distance teaching into the classroom teaching, and used interactive evaluation in distance education. A complete interactive evaluation consists of five phases: setup phase, submission phase, assessment phase, grading evaluation phase and closed phase. Results approved phase is completed, click "Close" to complete the whole interactive evaluation activities. students can seen the results of the submitted job.

5.1 Creating interactive evaluation and setup phase

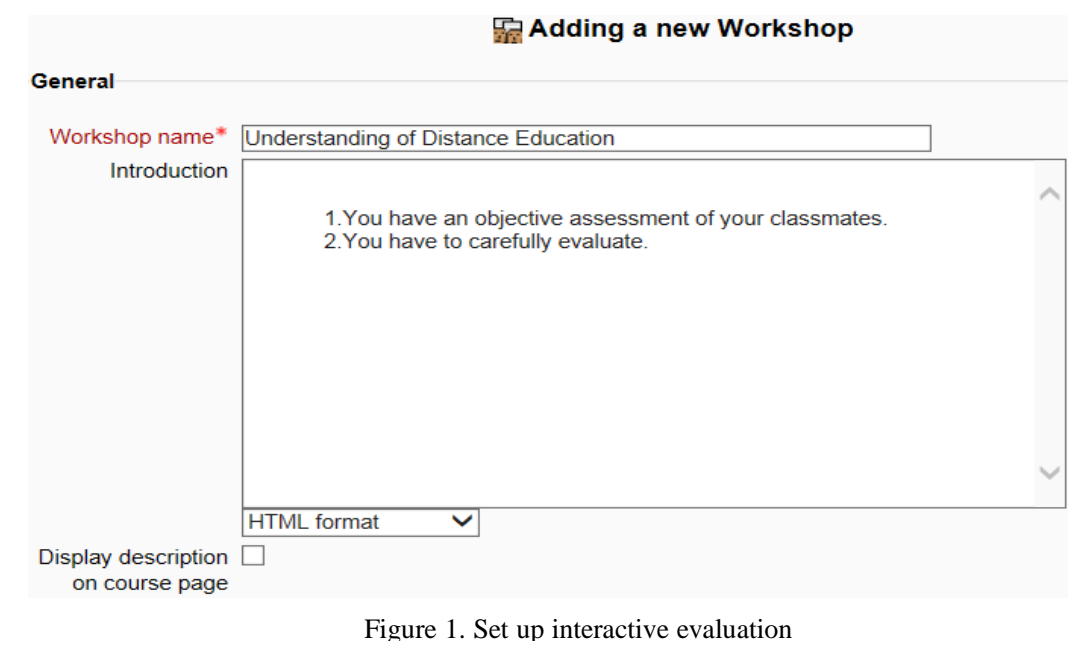

The teacher loged in "Distance Learning" page. Click "Tum editing on". The teacher from the "add an activity" list to selected "workshop", and entered the interactive evaluation of the editorial page. In this page,teacher can set the parameters of the interactive evaluation. Set the parameters as shown in Figure 1.

General.

The teacher can fill in the name and introduction of interactive evaluation, and tell the students to evaluate process and the results of evaluation of the composition.

Workshop features.

The teacher can choose whether to provide an example to the students to as the evaluation reference. The teacher can also decide whether the students have the right to self-assessment or evaluation of other students' jobs.

Grading settings.

Results are divided into grade for submission and grade for assessment. Grade for submission is the highest score for the evaluation of other students' work. Grade for assessment is based on the evaluation of fellow students (peer, himself), and for this evaluation is given the highest score. It also reviews the evaluation of teachers to students4. Score strategy is divided into accumulative grading, comments, number of errors and rubric. Accumulative grading - comments and a grade are given regarding specified aspects. Comments - comments are given regarding specified aspects but no grade can be given.

Number of errors - comments and a yes

or no 
assessment are given regarding specified assertions. Rubric - a level assessment is given regarding specified criteria. The number of decimal digits, you can set the number of decimal places after the decimal point, there are "0-5" six options5.

Submission settings.

In this part, the teacher can explain the students' homework. The teacher can set the maximum number of jobs to be uploaded. Each student can upload up to 7 attachments, each file can not exceed $2 \mathrm{MB}$. The teacher can also set whether to allow students to submit their assignments after the deadline. Assessment settings.

In this section, the teacher can explain the evaluation criteria and methods. If the teacher selects "Example submissions are provided for practice in assessing" in "workshop features" section, then this section will appear "mode of examples assessment". There are three options: Assessment of example submission is voluntary. Examples must be assessed before own submission. Examples are available after own submission and must be assessed before peer assessment. According to the specific need, the teacher can choose any of the three of them. As shown in Figure2.

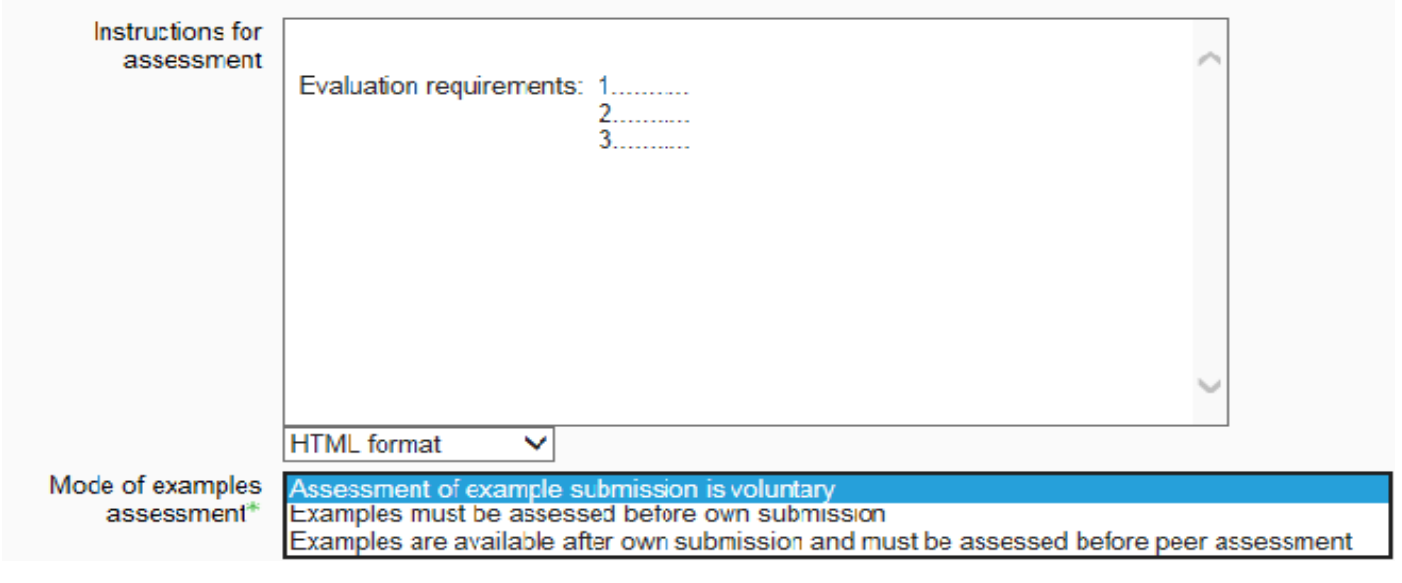

Figure 2. assessment settings

Access control.

In this section, the teacher can set the start time and the deadline for the job submission, and can also set the start time and the deadline for the assessment. In general, the evaluation time is later than the job submission time.Preferably, the students ' jobs are submitted to complete before starting the evaluation.

Common module settings.

In this section, the teacher sets the panel mode to the "visible groups", which can ensure the students to see the evaluation. The teacher sets the group mode as the "separate groups", which can not be realized. If the teacher sets the group mode to "no group", the students can only make a comment on the group members.

After the teachers have completed all the settings, clicked "Save and return to course" button. The teacher in the course page, click on the interactive evaluation name to enter the page shown in Figure 3. 
Understanding of Distance Education .

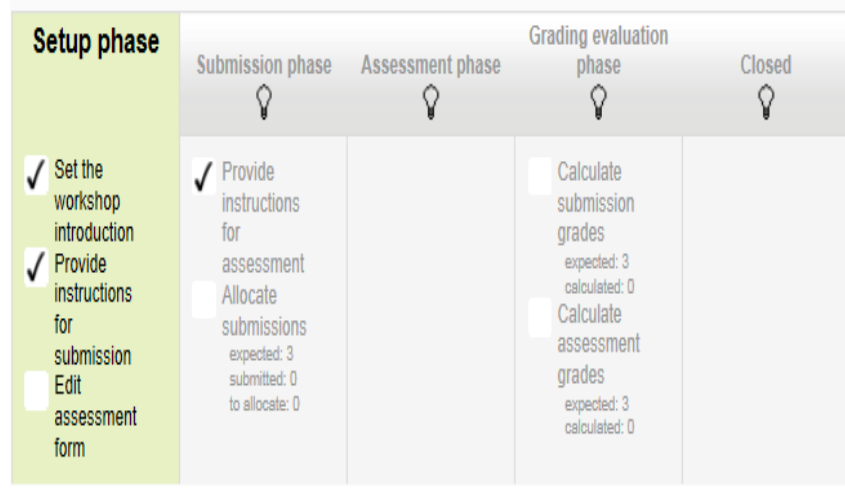

Figure 3. five phases

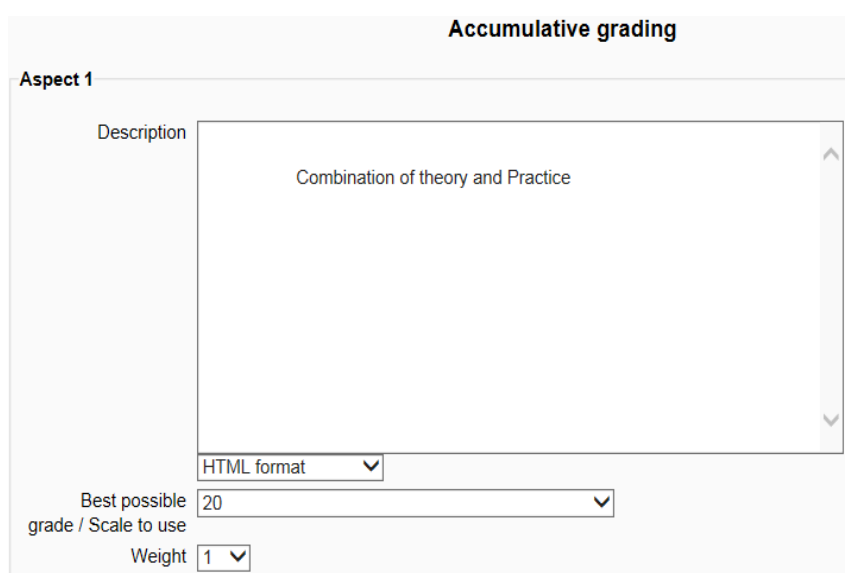

Figure 4. Set aspect

In setting the stage for the page, indicating " $\sqrt{ }$ " display has been set to complete steps, no " $\sqrt{ }$ display is not set to complete the steps. In this case, the teacher click "Edit assessment form". Teacher can edit points in the new page, as shown in figure 4. The teacher can choose the highest grade or score points. Each point has its own weight. The weight parameter is set to 1, which indicates that the weight of the teacher evaluation is the same as the weight of the students. The weight parameter is set to 0 , which indicates that the evaluation of the teacher does not affect the students' achievement. The weight parameter is set to the number greater than 1, which indicates that the weight of the teacher evaluation is higher than that of the students. Teacher evaluation of the weight is higher than the students, mainly on account of the evaluation, the students always give fellow high score or low score. By setting the weights, we can make up for the unreasonable evaluation, which helps maintain a fair and justice evaluation4. By default, the teacher can set up 3 points. If the teacher should increase the points, you can click "blanks for 2 more aspects", until the number increased to need so far. After the teacher to pick points setup are completed, click "Save and Close" button.

\subsection{Submission phase}

The task is to assign students' homework. First, Log in as administrator, administrator open "site administration" module in the "security / site policies" in the left side of the home page on moodle platform. Administrator find the " maximum time to edit posts " in the "site policy" page. This parameter defaults to thirty minutes, and then change to one minutes. So that the students after submitting the job one minute, you can enter the evaluation page. Second, log in to the course page as a teacher. The teacher clicked on the "turn editing on" button, then click on the "workshop" of the right side of the last button "assign roles ${ }^{2}$ ". Open the window as shown in Figure 5. In this window, the teacher clicked the "student" role button, and adds the right page "Optional user" to the left "has Users". Third, log in to the course page as a student, and then into the "submission phase". The student clicked on "submit" button to submit the job. Note that the student should submit his assignment in the specified time. Fourth, log in to the course page as a teacher, The teacher in "submission phase" click "allocate submissions" button. According to the assignment of students, the teacher can carry out manual allocation or assigned randomly. 


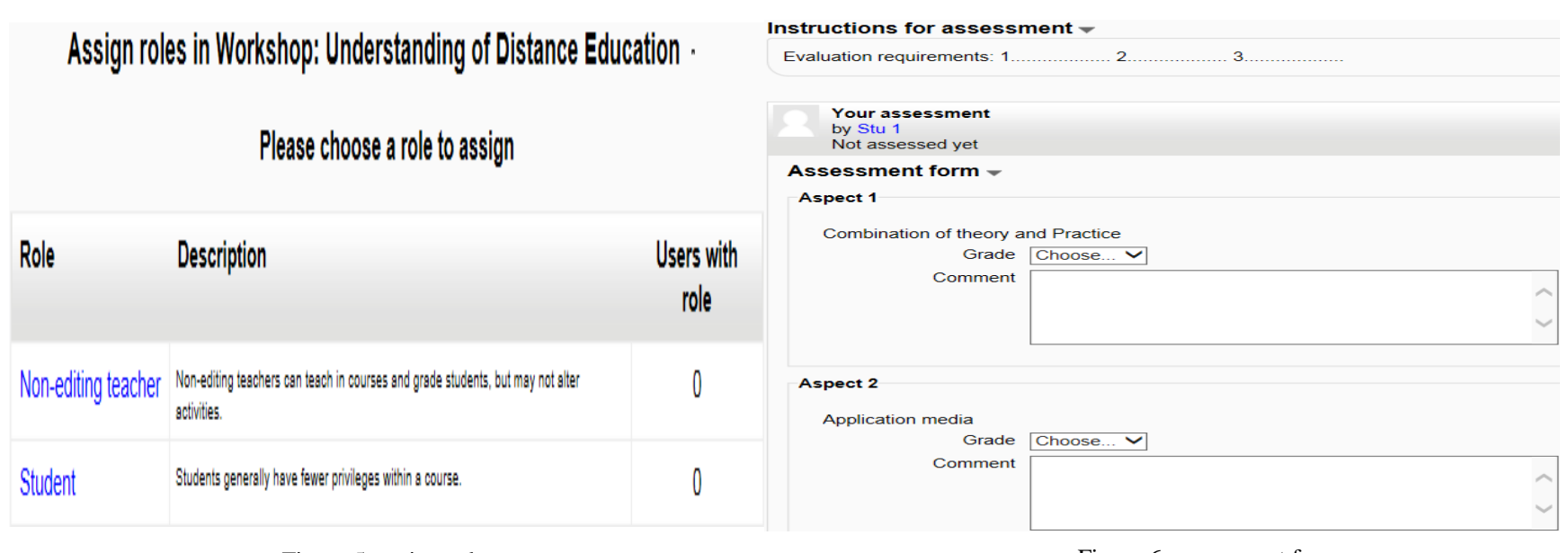

Figure 5. assign roles

Figure 6. assessment form

\subsection{Assessment phase}

Log in moodle platform as a teacher, and enter the "workshop" page. In the assessment phase, the evaluator can evaluate the job has been assigned to them. Students need to complete the evaluation of the work according to the score criteria. Log in to the course page as a student, interactive evaluation of the interface were show the evaluation method of teachers, were also show the need to evaluate the job. Student clicked on the "assess" button, the page were display the "assessment form". According to the requirements of mining points, student can give the scores and attach comments. As shown in Figure 6. If a student needs to modify the evaluation of others, he can click the "modify evaluation" button to modify the original evaluation. The teacher in the assessment phase tasks including evaluation of the students' work, evaluators conduct communication, evaluation of students re-evaluation and gave feedback on the evaluation of students.

\subsection{Grading evaluation phase}

At this stage, students can not modify their assignments and evaluation. The system will automatically calculate the student's final grade, and were feedback the evaluation results to the

evaluators. Log in moodle platform as a teacher, and enter the "workshop " page. The teacher clicked on the "re-calculate grades" button, the students' grade for submission and grade for assessment will be displayed. Teachers can click on the "grade for submission" and "grade for assessment" button on the right side of the ascending or descending order button, student achievement will be sorted in ascending or descending order.

\subsection{Closed}

Log in moodle platform as a teacher, and enter the "workshop " page. The teacher clicked the "button" at the bottom of the closed stage and clicked "continue" button on the page. In this case, the calculated results will be displayed on the report card. Students can log in moodle platform to view their assignments and evaluation of students` jobs.

\section{Conclusions}

mobilize the students' initiative, and make their learning attitude more serious, the teaching effect has been significantly improved.

Both for teachers and students, the moodle platform is very easy to operate. It has a good way to achieve the interaction between teachers and students. Especially the application of interactive 
evaluation, it is a major highlight of moodle applications. Through the application of the interactive evaluation of the moodle platform, the students can actively participate in the classroom teaching.It can mobilize the students`enthusiasm and initiative, so that students can put more enthusiasm into the study.

In teaching to make good use of interactive evaluation, we have to do the following: First, to ensure the stability of the network and the stable operation of the platform. Second, teachers and students are able to skillfully use the platform, so that the moodle as a tool for learning. Third, the teacher should put each student evaluation of the work quantity control in a certain range, to avoid fatigue evaluation. Fourth, the teacher should provide a detailed evaluation and operational paradigm, but also to set up detailed points. Fifth, the teacher can set up the monitor, the study members as non editing rights of the teacher. The teacher has different assignments to carry out the secondary evaluation. This will not only increase the sense of accomplishment and pride of class cadres, mobilize their enthusiasm, but also to reduce the burden on teachers.

Moodle platform can be applied to distance teaching. In classes of traditional universities can try to take advantage of interactive evaluation to carry on the mixed type teaching, as an effective supplement to classroom teachings.

\section{Acknowledgment}

In this paper, the research results of the project of Yunnan Provincial Department of education for 2014 years.Innovation and deep application of information technology and curriculum integration (number: 2014Y389). The study was helped by Professor Zhu Yundong. I express my heartfelt thanks.

\section{References}

[1]LIU Liyan,AN Heyi,GUO Zhongqiang.Exploring Network Education Applications Course Design based on Moodle Platform [J]. China Educational Technique \& Equipment,No18,2014:7-9

[2]PENG Hongying, Research on the application of interactive evaluation based on Moodle in Photoshop Teaching[J], Journal of Shanxi Normal University,( Natural Science), 2011.12: 73

[3]ZHU Aifen, The practice research of interactive evaluation based on Moodle platform[J], Educational technology and equipment in China,2013.10: 41-42

[4]XIAO Yizhen, A Study of Interactive Evaluation Based on the Moodle Platform Application in the Ideological and Political Theory Course[J],Journal of Zhejiang Wanli University, 2015.3: 89-91

[5]LI Jiahou, Information Course Design_-The creation of Information learning environment of Moodle[M], East China Normal University press, 2009.8:159-162

[6]YANG Yunying, The exploration of interaction design of network course based on moodle platform-taking "distance education foundation" as an example[J], Journal of Langfang Teachers University(Natural Science Edition), No4,2015:61-63 